\title{
To compare the effect of cyclizine, prochlorperazine and ondansetron in inhibiting postoperative nausea and vomiting following laparoscopic cholecystectomy
}

\author{
Anwaar Khurshid ${ }^{1}$, Muhammad Hamza Akram², Mohsan Nadeem Sheikh ${ }^{3}$ \\ 1,2,3. House Officer Bahawal Victoria Hospital, Bahawalpur \\ Correspoundng Author:anwaarqme@gmail.com
}

\begin{abstract}
:
Objective: To determine the efficacy of prochlorperazine, cyclizine and ondansetron in patients following laparoscopic cholecystectomy, in terms of prevention of vomiting and nausea. Study Type: Randomized Control Trial. Duration and Location of Study: Anaesthesia department of the Bahawal Victoria Hospital, Bahawalpur over a period of January, 2018 to January, 2019. Methodology: Total of 324 patients divided into Group P, group $\mathrm{O}$ and group $\mathrm{C}$ received prochlorperazine $(10 \mathrm{mg})$, ondansetron $(4 \mathrm{mg})$ and cyclizine $(50 \mathrm{mg})$ respectively. Every patient was asked to tell when he/she is feeling nauseous, vomited and used additional antiemetic drugs. Descriptive data was compared by applying ANOVA test and Chi-square or Fischer's exact test was applied on nominal data. Computer software SPSS version 23 was used to statistically analyze the data. $\mathrm{P} \leq 0.05$ was taken as significant., Results: Although occurrence of side effects was slightly higher in group-P, but all the groups were not statistically diffrent (p-value $0.581,0.500$ and 0.544 for headache, dizziness and sedation, respectively). Nausea and vomiting was observed in $4.6 \%$ in group-O patients, $5.5 \%$ in group-C patients and $8.3 \%$ in group-P patients, difference being statistically insignificant $(\mathrm{p}=0.500)$., Conclusion: From the results of this study it can be concluded that all the three drugs i.e. cyclizine, ondansetron and prochlorperazine are equally effective and there is no statistically significant difference in terms of prevention of vomiting and nausea in patients undergoing cholecystectomy through laparoscope.
\end{abstract}

Keywords: Ondansetron, Cyclizine, Prochlorperazine, postoperative nausea and vomiting

DOI: $10.7176 / \mathrm{JMPB} / 52-16$

\section{Introduction:}

Most common complaint is nausea and vomiting in patients within 24 to 48 hours following laparoscopic cholecystectomy and is called post-operative nausea and vomiting (PONV) ${ }^{1}$. Frequency of vomiting and nausea after operation is $30 \%$ to $50 \%$. Risk increased to $80 \%$ in the high risk patients. Brain, GI tract and vestibular system are involved in the pathophysiology of the nausea and vomiting following surgery ${ }^{2}$. Nausea, retching and vomiting are the three steps of the process of nausea and vomiting. Nausea is the feeling of a need to vomit; while retching is the contraction of abdominal wall muscles, muscles of chest and diaphragm that occur with nausea, reflexive forceful removal of the upper gastrointestinal contents through the oral cavity is called vomiting ${ }^{3}$. Feminine gender, smoking, past history of motion sickness and PONV are related with the higher risk of post-operative vomiting and nausea ${ }^{4}$. Incidence of PONV decreases with age in adult patients. Usage of volatile and inhalational anesthetics is connected with enhanced frequency of vomiting and nausea after operation. General anesthesia is associated with increased occurrence of PONV as compared to regional anesthesia ${ }^{10}$.

Incidence of PONV is also influenced by the type of surgical procedure. There is higher incidence in the head and neck, gynecological and in laparoscopic surgeries. Pneumoperitoneum is created during all the laparoscopic procedures which cause the increased frequency of PONV ${ }^{5}$. We are studying the effects of PONV in patients who underwent laparoscopic cholecystectomy. There are many serious complications in the patients undergoing laparoscopic cholecystectomy of vomiting and nausea which ranges from rapture of skin suture, bleeding from surgical spot, dehydration and aspiration pneumonia which cause delay in healing and increase in the duration of hospital stay which in turn causes the increase risk of nosocomial infection ${ }^{6}$. Any intervention which decreases the incidence of postoperative nausea and vomiting in patients would be beneficial and in this way complications of PONV can be avoided.

Anti-emetics are the drugs which are used for the prevention of postoperative nausea and vomiting. They block neuroreceptors which are involved in the pathway of emesis. There are many types of antiemetic drugs which include antihistamines $\left(\mathrm{H}_{1}\right.$ receptor antagonists), dopamine antagonists, serotonin receptor antagonists, $\mathrm{NK} 1$ receptor antagonists, cannabinoids, benzodiazepines, anticholinergics and steroids ${ }^{8}$. All classes of antiemetic drugs are associated with side effects like sedation, lethargy, skin sensitization, dry mouth, drowsiness, 
constipation, hypotension, restlessness, diarrhea, anxiety, insomnia, headache, prolongation of QT interval, muscle pain ${ }^{9}$. Ondansetron, cyclizine and prochlorperazine are the drugs which are used frequently in the avoidance of PONV in the patients who underwent laparoscopic cholecystectomy. Prochlorperazine is dopamine receptor antagonist, ondansetron is blocks the serotonin receptors and cyclizine blocks the histamine receptors. In our study we are going to compare the effectiveness of these drugs for preventing vomiting and nausea after operation in people undergoing laparoscopic cholecystectomy.

\section{Material n methods:}

A randomized control trail which was performed in Anaesthesia department of the Bahawal Victoria Hospital, Bahawalpur over a period of January, 2018 to January, 2019. Proper approval was obtained from hospital ethics committee. We obtained informed consent from all the patients before the start of the study. Study performed by Aamer $\mathrm{M}$ et al ${ }^{11}$ was used as reference to calculate the sample size. Non probability consecutive sampling was our method to select the patients. Patients who were going under laparoscopic cholecystectomy with ASA status I or II without any male to female preference were included. Age of the patients in this study ranges from 20 to 40 years. Patients with reflex esophagitis, pregnant females, peptic ulcer disease, antiemetic user, ASA status III and IV were excludes from the study. Patients who underwent emergency laparoscopic cholecystectomy and any drug allergy were also excluded from the study.

Total of three hundred and twenty four patients were involved in this study. We divided the patients into three groups. Group P included the patients who received prochlorperazine after laparoscopic cholecystectomy. Group $\mathrm{O}$ contained the patients who received ondansetron and Group $\mathrm{C}$ patients received cyclizine after laparoscopic cholecystectomy. Each group contains 108 patients. Patients were admitted in the hospital one day prior to surgery and pre-anesthesia evaluation of each patient is done by a consultant anesthesiologist who was not aware of the current study.

Before the induction of anesthesia none of the patient received any food or water for at least six hours. After that patients were shifted to the operation room where electrocardiography, pulse oximetry of every patient was done before, during and after the anesthesia induction. Blood pressure was monitored by non-invasive method during the whole process. Intravenous access was gained through a 16 gauge cannula. Fluids and electrolytes were replaced by using lactated ringer and gelofusine solution during the whole procedure of laparoscopic cholecystectomy. Mixture of midazolam, propofol and oxygen was used to induce anesthesia in every patient. Atracurium bromide was used for the relaxation of muscles and after achieving the relaxation laryngoscope blade was inserted into the mouth of every patient to achieve tracheal intubation by an appropriate sized endotracheal tube.

The study drugs with which every patient is going to be injected were prepared by a nurse who did not know about this trail. For the elimination of biasedness all the drugs were prepared in similar syringes. All the patients were given the drugs according to their groups. Group $\mathrm{P}$ received prochlorperazine $(10 \mathrm{mg})$, group $\mathrm{O}$ received ondansetron $(4 \mathrm{mg})$ and patients in the group $\mathrm{C}$ were given cyclizine $(50 \mathrm{mg})$. Isoflurane and Atracurium bromide were used for the maintenance of anesthesia if required. After completing the procedure of laparoscopic cholecystectomy neostigmine and glycopyrolate were given to every patient for the reversion of anesthesia. To clear the airway secretions are removed by applying gentle suction through the endotracheal tube. After clearing the secretions endotracheal tube was removed and patient is allowed to breathe on its own.

To note the incidence of PONV within a day after surgery help was taken by consultant anesthetists who were not aware of the groups of the patients. Every patient was asked to tell when he/she is feeling nauseous and every time he/she vomited. Usage of additional antiemetic drugs which are not part of this study for the avoidance of postoperative nausea and vomiting was also taken into account. Metoclopramide was the drug which was given to the patients if postoperative nausea and vomiting was not controlled by the study drugs. Side effects like dizziness, headache and restlessness of the study drugs were also noted in all the patients. Descriptive data was compared by applying ANOVA test and Chi-square or Fischer's exact test was applied on nominal data. Data was analyzed using SPSS v.23 and value of $\mathrm{p} \leq 0.05$ was considered statistically significant. Computer software SPSS version 23 was used to statistically analyze the data. $\mathrm{P} \leq 0.05$ was taken as significant. 


\section{Results:}

In currents study, the difference in the age was not significant ( $P$ value 0.067$)$, male to female ratio $(p=0.697)$, ASA-I and ASA-II class patients $(\mathrm{p}=0.892)$, and body mass index $(\mathrm{p}=0.251)$. The duration of anesthesia and surgery was also not significantly different (p-value 0.550 and 0.526 , respectively). (Table-I)

Although occurrence of side effects was slightly higher in group-P, but the difference among all the groups was not statistically significant (p-value $0.581,0.500$ and 0.544 for headache, dizziness and sedation, respectively). Nausea and vomiting was observed in $4.6 \%$ in group-O patients, $5.5 \%$ in group-C patients and $8.3 \%$ in group-P patients but there was no statistically significant difference (P value 0.500). Emergency anti-emetic medication was required by $4.6 \%$ of the patients in group-O, $3.7 \%$ of the patients in group-C and $7.4 \%$ of the patients in group$\mathrm{P}(\mathrm{p}=0.446)$. (Table-II)

Table-I

Baseline Characteristics

\begin{tabular}{|l|c|c|c|c|}
\hline \multicolumn{1}{|c|}{ Baseline Characteristics } & Group $\mathbf{~} \mathbf{n}=\mathbf{1 0 8}$ & Group $\mathbf{~} \mathbf{n}=\mathbf{1 0 8}$ & Group P $\mathbf{n = 1 0 8}$ & P value \\
\hline Age $($ years) & $36.42 \pm 4.72$ & $36.70 \pm 4.60$ & $35.33 \pm 4.32$ & 0.067 \\
\hline Male $(\mathrm{n})$ & 66 & 62 & 68 & 0.697 \\
\hline ASA-l/ASA-II & $94 / 14$ & $96 / 12$ & $94 / 14$ & 0.892 \\
\hline BMI (kg/m ${ }^{2}$ ) & $24.35 \pm 3.63$ & $24.31 \pm 3.99$ & $25.06 \pm 3.53$ & 0.251 \\
\hline Anesthesia Duration $(\mathrm{min})$ & $109.31 \pm 17.59$ & $111.87 \pm 17.72$ & $110.42 \pm 16.48$ & 0.550 \\
\hline Surgery Duration $(\mathrm{min})$ & $104.75 \pm 14.70$ & $105.83 \pm 14.50$ & $103.60 \pm 14.17$ & 0.526 \\
\hline
\end{tabular}

Data is presented as mean \pm S.D or number; ASA=American society of anesthesiologists.

Table-II

\section{Comparison of Side Effects}

\begin{tabular}{|l|c|c|c|c|}
\hline \multicolumn{1}{|c|}{ Side Effects } & Group $\mathbf{~}$ n=108 & Group C $\mathbf{n = 1 0 8}$ & Group P $\mathbf{n = 1 0 8}$ & P value \\
\hline Headache & $8(7.4)$ & $7(6.5)$ & $11(10.2)$ & 0.581 \\
\hline Dizziness & $6(5.5)$ & $5(4.6)$ & $9(8.3)$ & 0.500 \\
\hline Sedation & $7(6.5)$ & $6(5.5)$ & $10(9.3)$ & 0.544 \\
\hline Need for Rescue anti-emetics & $5(4.6)$ & $4(3.7)$ & $8(7.4)$ & 0.446 \\
\hline
\end{tabular}

Data is presented as number (percentage)

\section{Discussion:}

In our study we deduced that the efficacy of all three drugs in controlling vomiting and nausea after operation is comparable and no significant difference occur in the effectiveness of these drugs. Side effects like headache, sedation and dizziness were observed more in group $\mathrm{P}$ patients as compared to group $\mathrm{C}$ and group O. Additional use of antiemetic drugs is less for the group $\mathrm{C}$ patients in comparison to group $\mathrm{P}$ and group $\mathrm{O}$.

Aamer $\mathrm{M}$ et al. ${ }^{11}$ in their study conducted on 195 patients of laparoscopic cholecystectomy. They divide the patients into 3 groups and give them ondansetron, prochlorperazine and cyclizine according to their groups to control vomiting and nausea. On completing their study they said that these drugs are equally effective in the patients undergoing laparoscopic cholecystectomy to control vomiting and nausea which occur after operation. Grimsehl K et al. ${ }^{12}$ did their study on seventy four patients of laparoscopic surgery and divide the patients into two groups. They give one group cyclizine and the other group ondansetron. They concluded that both the drugs are equally capable of preventing postoperative nausea and vomiting and there is no delay in discharge from hospital by using these drugs although they found that cyclizine is less expansive as compared to ondansetron. Singhal A et al. ${ }^{13}$ did a review of different randomized trials to know the dissimilarity in the efficacy of the $5 \mathrm{HT}_{3}$ antagonist (ondansetron) for inhibiting PONV as compared to all other drugs which are used to control vomiting and nausea after operation. They said that the $5 \mathrm{HT}_{3}$ antagonists are better in preventing postoperative nausea and vomiting as compared to other drugs. Peter $\mathrm{S}$ et al. ${ }^{14}$ did the systemic review of the 41 trails and they compared the efficacy of drugs like cyclizine, prochlorperazine and metoclopramide with that of the ondansetron and 
granisetron. They concluded that the $5 \mathrm{HT}_{3}$ antagonists are better for the prevention of the PONV. Catriona $\mathrm{R}^{15}$ comes to a conclusion that no group of antiemetic drug is better than the other in the prevention of postoperative nausea and vomiting.

Khaterah I et al. ${ }^{16}$ conducted a study on the sixty patients of laparoscopic cholecystectomy and divide the patients into two groups. One group received ondansetron and the other group received metoclopramide which is also a dopamine receptor antagonist and they found that efficacy of both drugs was comparable in terms of prevention of vomiting and nausea in patients undergoing laparoscopic cholecystectomy. In a study on the seventy eight patients undergoing hip or knee replacement it was concluded that the prochlorperazine is cheap drug as compared to ondansetron and there is less usage of additional antiemetic drugs with prochlorperazine. Trichak $\mathrm{S}$ et al. ${ }^{18}$ studied the eighty patients undergoing laparoscopic cholecystectomy and they noted that the efficacy of ondansetron is higher in preventing PONV as compared to dopamine receptor antagonist metoclopramide. Cholwill $\mathrm{J}$ et al. ${ }^{7}$ conducted a double blind study to compare the effectiveness of cyclizine and ondansetron with that of placebo and they noticed that the incidence of PONV is very less in the patients who received ondansetron or cyclizine when compared with placebo and there is no difference in the efficacy of ondansetron and cyclizine.

\section{Conclusion}

From the results of this study it can be concluded that all the three drugs i.e. cyclizine, ondansetron and prochlorperazine are equally effective and there is no statistically significant difference in terms of prevention of vomiting and nausea in patients undergoing cholecystectomy through laparoscope.

\section{Conflict of interest: nil}

Funding Source: nil

\section{References:}

1. Öbrink E, Jildenstål P, Oddby E, Jakobsson JG. Post-operative nausea and vomiting: update on predicting the probability and ways to minimize its occurrence, with focus on ambulatory surgery. Int J Surg. 2015;15:100-6.

2. Horn CC, Wallisch WJ, Homanics GE, Williams JP. Pathophysiological and neurochemical mechanisms of postoperative nausea and vomiting. Eur J Pharmacol. 2014 ;722:55-66.

3. Sanzari JK et al. Effects of solar particle event proton radiation on parameters related to ferret emesis. Radiat Res. 2013 ;180(2):166-76.

4. Hambridge K. Assessing the risk of post-operative nausea and vomiting. Nurs stand (through 2013). 2013 ;27(18):35

5. Gauchan S, Thapa C, Shakya P, Bhattarai R, Shakya S. Ondansetron and Granisetron for prevention of postoperative nausea and vomiting following laparoscopic cholecystectomy. J Nepal Med Assoc. 2014;52(193):682-.

6. Ismail S, Ahmed A, Hoda MQ, Sohaib M. Prospective survey to study factors which could influence sameday discharge after elective laparoscopic cholecystectomy in a tertiary care hospital of a developing country. Updat Surg . 2016 ;68(4):387-93.

7. Cholwill JM, Wright W, Hobbs GJ, Curran J. Comparison of ondansetron and cyclizine for prevention of nausea and vomiting after day-case gynaecological laparoscopy. Brit J Anaesth. 1999; 83(4):611-4.

8. Gan TJ et al.. Consensus guidelines for the management of postoperative nausea and vomiting. Anesth Analg. 2014 ;118(1):85-113.

9. D'Souza RS et al. Effects of prophylactic anticholinergic medications to decrease extrapyramidal side effects in patients taking acute antiemetic drugs: a systematic review and meta-analysis. Emerg Med J. 2018 :emermed-2017.

10. Wang XX, et al. Comparison of postoperative events between spinal anesthesia and general anesthesia in laparoscopic cholecystectomy: a systemic review and meta-analysis of randomized controlled trials. Biomed res int. 2016;2016. 
11. Malak AM, Shameem A, Ali CA, Qureshi MA. Comparison of ondansetron, cyclizine and prochlorperazine for PONV prophylaxis in laparoscopic cholecystectomy. Anaesth P Inten. 2017;21(4):453-7

12. Grimsehl K, Whiteside JB, Mackenzie N. Comparison of cyclizine and ondansetron for the prevention of postoperative nausea and vomiting in laparoscopic day-case gynaecological surgery. Anesth. 2002 ;57(1):63-7.

13. Singhal AK, Kannan S, Gota VS. 5HT 3 antagonists for prophylaxis of postoperative nausea and vomiting in breast surgery: A meta-analysis. J Postgrad Med. 2012 ;58(1):23.

14. Loewen PS, Marra CA, Zed PJ. 5-HT 3 receptor antagonistsvs traditional agents for the prophylaxis of postoperative nausea and vomiting. Can J Anaesth. 2000 ;47(10):1008-18.

15. Rother C. Post-Operative Nausea \& Vomiting-Use of Anti-Emetic Agents in Anaesthesia. Scot Univ Med J . $2012 ; 1(1)$.

16. Isazadehfar K, Entezariasl M, Shahbazzadegan B, Nourani Z, Shafaee Y. The comparative study of ondansetron and metoclopramide effects in reducing nausea and vomiting after laparoscopic cholecystectomy. Acta Med Iran. 2017;55(4):254-8.

17. Chang P. Cost-EffectivenessAnalysis of Ondansetron and Prochlorperazine for the Prevention of Postoperative Nausea andVomiting. J Manage Care Pharm. 2005(4):317-21.

18. Sandhu T, Tanvatcharaphan P, Cheunjongkolkul V. Ondansetron versus metoclopramide in prophylaxis of nausea and vomiting for laparoscopic cholecystectomy: a prospective double-blind randomized study. Asian J Surg 2008; 31(2):50-4. 